OPEN ACCESS

Edited by:

Peregrine B. Osborne,

The University of Melbourne, Australia

Reviewed by:

Mariana Spetea,

University of Innsbruck, Austria

Ewa Krystyna

Szczepanska-Sadowska,

Medical University of Warsaw, Poland

*Correspondence:

Yanjie Yang

yangyj@henu.edu.cn

Xinchun Wang

wxc619533@sina.com

${ }^{\dagger}$ These authors have contributed equally to this work

Specialty section:

This article was submitted to

Neuropharmacology,

a section of the journa

Frontiers in Neuroscience

Received: 19 April 2020

Accepted: 11 August 2020

Published: 08 September 2020

Citation:

LV S, Zhang $X$, Feng $Y$, Zhou $Y$,

Cui $B$, Yang $Y$ and Wang $X(2020)$

Intravenous Administration

of Pyroglutamyl Apelin-13 Alleviates

Murine Inflammatory Pain via

the Kappa Opioid Receptor.

Front. Neurosci. 14:929.

doi: 10.3389/fnins.2020.00929

\section{Intravenous Administration of Pyroglutamyl Apelin-13 Alleviates Murine Inflammatory Pain via the Kappa Opioid Receptor}

\author{
Shuangyu Lv't, Xiaomei Zhang ${ }^{1 \dagger}$, Yu Feng ${ }^{1}$, Yuchen Zhou' ${ }^{1}$, Binbin Cui', Yanjie Yang ${ }^{1 *}$ \\ and Xinchun Wang ${ }^{2 *}$
}

${ }^{1}$ Institute of Molecular Medicine, School of Basic Medical Sciences, Henan University, Kaifeng, China, ${ }^{2}$ Key Laboratory of Clinical Resources Translation, The First Affiliated Hospital of Henan University, Kaifeng, China

Apelin is an endogenous neuropeptide, which has wide distribution in central nervous system and peripheral tissues. Pyroglutamyl apelin-13 [(pyr)apelin-13] is the major apelin isoform in human plasma. However, the role of peripheral (pyr)apelin-13 in pain regulation is unknown. The aim of this study was to investigate the effect of the peripheral injection of (pyr)apelin-13 on inflammatory pain using the formalin test as well as to evaluate the mechanistic basis for the effect. Results showed intravenous (i.v.) injection of (pyr)apelin-13 (10, $20 \mathrm{mg} / \mathrm{kg})$ to significantly decrease licking/biting time during the second phase of the mouse formalin test. In contrast, i.v. injection of apelin-13 had no influence on such effect. Intramuscular injection of (pyr)apelin13 reduced licking/biting time during the second phase only at a dose of $20 \mathrm{mg} / \mathrm{kg}$. The antinociception of i.v. (pyr)apelin-13 was antagonized by the apelin receptor (APJ, angiotensin II receptor-like 1) antagonist, apelin-13(F13A). (pyr)apelin-13 (i.v. $20 \mathrm{mg} / \mathrm{kg}$ ) markedly upregulated Aplnr and Adcy2 gene expression in the prefrontal cortex, whereas Fos gene expression was downregulated. The antinociception of i.v. (pyr)apelin-13 was blocked by the opioid receptor antagonist naloxone and the specific kappa opioid receptor (KOR) antagonist nor-binaltorphimine (nor-BNI). (pyr)Apelin-13 upregulated the dynorphin and KOR gene expression and protein levels in the mouse prefrontal cortex, not in striatum. (pyr)Apelin-13 did not influence the motor behavior. Our results demonstrate that i.v. injection of (pyr)apelin-13 induces antinociception via the KOR in the inflammatory pain mouse model.

Keywords: (pyr)apelin-13, inflammatory pain, opioid receptor, dynorphin, prefrontal cortex

\section{INTRODUCTION}

Apelin, also known as APLN, is the endogenous ligand for the apelin receptor (APJ, angiotensin II receptor-like 1), an orphan G protein-coupled receptor (GPCR) (Tatemoto et al., 1998). APJ, also known as APLNR, was originally identified by O'Dowd et al. (1993). The APJ receptor is composed of 380 amino acid residues, the sequence of which has considerable similarity to that 
of the angiotensin II type 1 (AT1) receptor (54\% for the transmembrane domains and $30 \%$ for the entire sequence). Nevertheless, angiotensin II does not bind to APJ (O'Dowd et al., 1993). Apelin is an endogenous peptide, which was first isolated from bovine stomach extracts (Tatemoto et al., 1998). The preproprotein of apelin (known as preproapelin) consists of 77 amino acids, coded by APLN which is located on chromosome Xq25-26.1 (Lee et al., 2000). When preproapelin was enzymatically hydrolyzed, several bioactive fragments are produced, including apelin-36, apelin-19, apelin-17, apelin-13, and apelin-12 (Habata et al., 1999; Hosoya et al., 2000). It is notable that (pyr)apelin-13, the pyroglutamate modified form of apelin-13, was identified as the major apelin isoform in human plasma (Zhen et al., 2013). (pyr)Apelin-13 was shown to be more structurally stable than apelin-13 (Hosoya et al., 2000) in that the $\mathrm{N}$-terminal pyr protects from exopeptidase degradation (Masri et al., 2005). A clinical study demonstrated that (pyr)apelin13 was to be the predominant cardiac isoform in patients with coronary artery disease (Maguire et al., 2009).

The apelin/APJ system is involved in multiple physiological and pathophysiological functions, including cardiovascular regulation, cancer (Yang et al., 2016; Patel et al., 2017), ischemia/reperfusion injury (Yang et al., 2015), fluid homeostasis, angiogenesis (O'Carroll et al., 2013), and liver metabolism (Lv et al., 2017). Recently, a role for the apelin/APJ system in neurological disease and mental disorders has attracted considerable attention (Lv S.-Y. et al., 2020). Intracerebroventricular (i.c.v.) injection of apelin attenuated depressive-like behavior in rats with chronic stress (Dai et al., 2018; Zhang et al., 2019). Apelin-13 (i.c.v.) alleviated memory performance deficits in a rat model of chronic water-immersion restraint stress (Shen et al., 2019) and cognitive deficits in a streptozotocin-induced rat model of Alzheimer's disease (Luo et al., 2019), each of which was mediated by brainderived neurotrophic factor (BDNF) signaling. Fan et al. (2017, 2018) found that intraperitoneal (i.p.) injection of apelin-13 significantly mitigates mouse anxiety-like behavior induced by chronic normobaric hypoxia by inhibition of the nuclear factor kappa-B (NF-кB) pathway. In addition, apelin had anti-neuroinflammatory (Zhou et al., 2019), anti-apoptotic, and neuroprotective effects (Liu et al., 2019). Further, apelin played a role in Parkinson's disease (Acar et al., 2019) and post-traumatic stress disorder (Chen et al., 2019).

Apelin/APJ genes were ubiquitously expressed in various organs of humans and rodents, with the highest expression in lung, heart, adipose tissue, brain, gastrointestinal tract, liver, kidney, and the cardiovascular system (Habata et al., 1999; Kawamata et al., 2001; Medhurst et al., 2003). Apelin and APJ had been detected in the amygdala, hypothalamus, dorsal raphe nucleus (DRN), and the spinal cord (Hosoya et al., 2000; O'Carroll et al., 2000; Reaux et al., 2001), which were anatomic sites of descending pain modulation pathways. Our previous report showed that i.c.v. and intrathecal (i.t.) administration of apelin-13 induced an antinociceptive effect in an acetic acid-induced mouse visceral pain model (Lv et al., 2012). However, a role for peripheral (pyr)apelin-13 in inflammatory pain is unknown.
The formalin-test pain model is more relevant to clinical pain than other models in that the pain response is evoked by a continuous and acute stimulus that is reproducible and quantifiable (Reeta et al., 2006). This model is used to assess potential antinociceptive agents, and it has two pain phases, a first (early) phase and a second (late) phase. The first phase is initiated by direct stimulation of nociceptors and the second phase develops in parallel with inflammatory processes (Dubuisson and Dennis, 1977). The present study was designed to assess the effect of intravenous (i.v.) injection and intramuscular (i.m.) injection of (pyr)apelin-13 on the inflammatory pain induced by the formalin test. The mechanistic basis for the underlying effect was explored by quantitative real-time polymerase chain reaction (RT-qPCR), western blot, and ELISA.

\section{MATERIALS AND METHODS}

\section{Animals}

Male Kunming mice (6-8 weeks of age, $20 \pm 1 \mathrm{~g}$ ) were supplied by the Animal Center of Henan Province (Zhengzhou, China). The animals were kept in standard cages (5-6 mice/cage) in a room at $22 \pm 1^{\circ} \mathrm{C}$, with a $12 \mathrm{~h} / 12 \mathrm{~h}$ light/dark cycle, $50-60 \%$ relative humidity, free access to water, and standard food. The mice were allowed to adapt to this environment for at least 7 days before experiments. This study and the animal experimental protocols were performed in accordance with the Committee of Medical Ethics and Welfare for Experimental Animals, Henan University School of Medicine (No. HUSOM2016-042).

\section{Chemicals and Drug Administration}

The peptides, apelin-13, (pyr)apelin-13, and apelin-13(F13A) were obtained from GL Biochem (Shanghai) Ltd. (Shanghai, China). The amino acid sequence of (pyr)apelin-13 was "PyrArg-Pro-Arg-Leu-Ser-His-Lys-Gly-Pro-Met-Pro-Phe," and the amino acid sequence of apelin-13 was "Gln-Arg-Pro-ArgLeu-Ser-His-Lys-Gly-Pro-Met-Pro-Phe.” Apelin-13(F13A) was the APJ receptor antagonist. Morphine hydrochloride was supplied by The First Affiliated Hospital of Henan University (Kaifeng, China). Naloxone (opioid receptor antagonist) and nor-binaltorphimine dihydrochloride (nor-BNI, KOR antagonist) were purchased from Sigma-Aldrich (St. Louis, MO, United States). The chemicals were dissolved in sterile saline and stored at $-20^{\circ} \mathrm{C}$ until the time of injection. The drugs were i.v. injected into mouse tail veins at a constant rate of $0.01 \mathrm{ml}$ per second or were intramuscularly (i.m.) administered into buttock sites in a volume of $0.1 \mathrm{ml}$.

\section{Formalin Test}

A model of acute inflammatory pain was established using the formalin test. The test was performed as described previously (Tjolsen et al., 1992; Lv et al., 2013). Briefly, the animals were placed into a transparent glass cylinder (height, $20 \mathrm{~cm}$; diameter, $15 \mathrm{~cm}$ ) individually, with a mirror angled at $45^{\circ}$ below the surface of the cylinder that allowed free viewing of nociceptiverelated behaviors. For adaptation the mice were placed in the glass cylinder $30 \mathrm{~min}$ before testing. After habituation, a 1.0\% 
formalin solution was intraplantar (i.pl.) injected into the dorsal surface of the right hind paw in a volume of $20 \mu \mathrm{l} /$ mouse. The amount of time the animal spent licking or biting the injected paw was recorded for $30 \mathrm{~min}$ using a stopwatch. The time period from 0 to $10 \mathrm{~min}$ (phase 1) represents the acute pain phase (early phase) and the time period from 10 to $30 \mathrm{~min}$ (phase 2) represents the inflammatory pain phase (late phase). The observers (X.Z. and Y.F.) were blind to the study protocol.

In formalin test, the experiment consisted of four sections: (1) To evaluate the analgesic effects of peripheral (pyr)apelin-13, (pyr)apelin-13 were administered by i.v. $30 \mathrm{~min}$ before formalin treatment. Morphine served as a positive control. In this section, animals were divided into five groups: saline $(n=10), 2 \mathrm{mg} / \mathrm{kg}$ (pyr)apelin-13 ( $n=9), 10 \mathrm{mg} / \mathrm{kg}$ (pyr)apelin-13 $(n=8), 20 \mathrm{mg} / \mathrm{kg}$ (pyr)apelin-13 $(n=8)$, and $2 \mathrm{mg} / \mathrm{kg}$ morphine $(n=9)$. (2) To examine the analgesic effects of peripheral (pyr)apelin-13, mice were divided four groups: saline $(n=10)$ and apelin-13 $(2,10$, and $20 \mathrm{mg} / \mathrm{kg} ; n=8,7$, and 8 , respectively). The drugs were i.v. injected $30 \mathrm{~min}$ before formalin treatment. (3) To examine the analgesic effects of i.m. (pyr)apelin-13, mice were divided four groups: saline $(n=9)$, (pyr)apelin-13 (10 and $20 \mathrm{mg} / \mathrm{kg}$; $n=9$ and 9, respectively), and morphine (2 $\mathrm{mg} / \mathrm{kg}, n=8)$. The saline or (pyr)apelin-13 was i.m. injected $30 \mathrm{~min}$ before formalin treatment. (4) To explore the potential mechanism of the antinociception induced by (pyr)apelin-13, the animals were divided into six groups: saline $(n=10), 20 \mathrm{mg} / \mathrm{kg}$ (pyr)apelin$13(n=8), 20 \mathrm{mg} / \mathrm{kg}$ apelin-13(F13A) $(n=8), 2 \mathrm{mg} / \mathrm{kg}$ naloxone $(n=8), 10 \mathrm{mg} / \mathrm{kg}$ nor-BNI $(n=8), 20 \mathrm{mg} / \mathrm{kg}$ (pyr)apelin$13+20 \mathrm{mg} / \mathrm{kg}$ apelin-13(F13A) $(n=8), 20 \mathrm{mg} / \mathrm{kg}$ (pyr)apelin$13+2 \mathrm{mg} / \mathrm{kg}$ naloxone $(n=7)$, and $20 \mathrm{mg} / \mathrm{kg}$ (pyr)apelin$13+10 \mathrm{mg} / \mathrm{kg}$ nor-BNI $(n=8)$.

All the saline or chemicals [apelin13, (pyr)apelin-13, or antagonists] were i.v./i.m. injected $30 \mathrm{~min}$ before i.pl. injection of formalin. The dose of (pyr)apelin-13 was selected according to the previous reports (Chen et al., 2015; Gourdy et al., 2018). Each antagonist [apelin-13(F13A), naloxone, and nor-BNI] was mixed with (pyr)apelin-13 and then i.v. co-administered in a volume of $100 \mu \mathrm{l}$ at one time point, respectively. This coadministrated administration method was selected following the previous reports ( $\mathrm{Lv}$ et al., 2012, 2013), and this procedure is to minimize the total injection volume and ascertain that the compounds were similarly localized.

To investigate potential gene(s) or protein(s) involved in antinociception induced by (pyr)apelin-13, $30 \mathrm{~min}$ after i.v. treatment with $20 \mathrm{mg} / \mathrm{kg}$ (pyr)apelin-13 or saline, mice were i.pl. injected with formalin. Thirty minutes later, the brain tissues (prefrontal cortex, striatum, etc.) were removed, snap frozen in liquid nitrogen, and stored at $-80^{\circ} \mathrm{C}$ until analyzed by RT-qPCR, ELISA, or western blot.

\section{RNA Isolation and Reverse Transcription}

Frozen brain tissue was homogenized (Power Gen 125; Fisher Scientific, Pittsburgh, PA, United States) and total RNA was isolated using TRIzol Reagent (Invitrogen, Thermo Fisher Scientific, Carlsbad, CA) based on the manufacturer's protocol. The concentration of the sample was measured with a NanoDrop
2000 UV-Vis Spectrophotometer (Thermo Fisher Scientific, Wilmington, DE, United States) and the concentration of RNA was measured by OD260/OD280. Total RNA was reverse transcribed to complementary DNA (cDNA) using a High Capacity cDNA Reverse Transcription kit (Applied Biosystems, Foster City, CA) following the product's instruction. During the process, M-MLV reverse transcriptase and oligo dT (200 U/ $\mu \mathrm{l})$ were applied in a final volume of $50 \mu \mathrm{l}$.

\section{RT-qPCR}

The mRNA levels were assessed for the APJ receptor (Aplnr), proopiomelanocortin (Pomc), prodynorphin (Pdyn), proenkephalin (Penk), mu opioid receptor (Oprm1), KOR (Oprk1), delta opioid receptor (Oprd1), adenylate cyclase 1 $(A d c y 1)-A d c y 9$, brain-derived neurotrophic factor $(B d n f)$, FBJ osteosarcoma oncogene (Fos), CAMP responsive element binding protein 1 (Creb1), down-regulator of transcription 1 (Dr1), early growth response protein 1 (Egr1), mitogen-activated protein kinase $14(p 38 \alpha)$, and signal transducer and activator of transcription 2 (Stat2). RT-qPCR was carried out with a $7500 \mathrm{HT}$ thermal cycler (Applied Biosystems) and SYBR Green master mix (Invitrogen, South San Francisco, CA, United States). The sequence of primers used for RT-qPCR assays are listed in Table 1 and were designed following previous reports. The gene for 36B4 was included as an endogenous control. After each RTqPCR, dissociation curve analysis was conducted to ensure the specificity of the PCR amplification. The normalized expression of the target genes was calculated with the equation $2^{-\Delta \Delta \mathrm{Ct}}$, and the $\Delta \Delta \mathrm{Ct}=(\mathrm{Ct} \text {, Target }-\mathrm{Ct}, 36 \mathrm{~B} 4)_{\mathrm{drug}}-(\mathrm{Ct} \text {, Target }-\mathrm{Ct}, 36 \mathrm{~B} 4)_{\text {control }}$.

\section{ELISA}

Blood and prefrontal cortex were removed from mice $1 \mathrm{~h}$ after i.v. administration of (pyr)apelin-13 or saline. Brains were weighed, homogenized with $10 \% \mathrm{w} / v$ phosphate buffer $(0.1 \mathrm{M}$, $\mathrm{pH} 7.4$ ), and centrifuged at $10,000 \mathrm{rpm}$ for $15 \mathrm{~min}$ at $4^{\circ} \mathrm{C}$. Serum was obtained by centrifugation of blood at $4000 \mathrm{rpm}$ at $4^{\circ} \mathrm{C}$ for $5 \mathrm{~min}$. Brain supernatants and serum were assessed for dynorphin content using the Mouse Dynorphin ELISA Kit (Shanghai Fusheng Shiye Co. Ltd., Shanghai, China) according to the manufacturer's protocol.

\section{Western Blot}

Protein lysates of mouse brain tissue were prepared in RIPA:PMSF (100:1) supplemented with phosphatase inhibitors. Protein concentrations were measured by the bicinchoninic acid assay (Beyotime, Shanghai, China). Samples were subjected to sodium dodecyl sulfate polyacrylamide gel electrophoresis (SDSPAGE) and then transferred to polyvinylidene difluoride (PVDF) membranes (Pall, East Hills, NY, United States). The PVDF membranes were blocked with 5\% skim milk and incubated with primary antibodies reactive with $\operatorname{KOR}$ (1:1000; Abcam, Cambridge, MA, United States) or beta-actin (1:1000; Beyotime), at $4^{\circ} \mathrm{C}$ overnight. The blots were then incubated with horseradish peroxidase (HRP)-labeled secondary antibody (Proteintech, Shanghai, China) for $1 \mathrm{~h}$. The membrane was incubated with SuperSignal West Pico Chemiluminescent Substrates (Thermo Fisher Scientific, Waltham, MA, United States) and bands 
TABLE 1 | Primer sequence used for RT-qPCR.

\begin{tabular}{|c|c|c|}
\hline Primer name & Primer sequence & Size (bp) \\
\hline Aplnr-F & 5'-CCACCTGGTGAAGACTCTCTACA-3' & 110 \\
\hline Aplnr-R & 5'-TGACATAACTGATGCAGGTGC-3' & \\
\hline Pomc-F & 5'-AGATTCAAGAGGGAGCTGGA-3' & 159 \\
\hline Pomc-R & 5'-CTTCTCGGAGGTCATGAAGC-3' & \\
\hline Pdyn-F & 5'-CGGAACTCCTCTTGGGGTAT-3' & 154 \\
\hline Pdyn-R & 5'-TाTGGCAACGGAAAAGAATC-3' & \\
\hline Penk-F & 5'-AACAGGATGAGAGCCACTTGC-3' & 474 \\
\hline Penk-R & 5'-CTTCATCGGAGGGCAGAGACT-3' & \\
\hline Oprm1-F & 5'-АTCCTCTCTTCTGCCATTGGT-3' & 127 \\
\hline Oprm1-R & 5'-TGAAGGCGAAGATGAAGACA-3' & \\
\hline Oprd1-F & 5'-AAGTACTTGGCGCTCTGGAA-3' & 125 \\
\hline Oprd1-R & 5'-GCTCGTCATGTTTGGCATC-3' & \\
\hline Oprk1-F & 5'-CCGATACACGAAGATGAAGAC-3' & 341 \\
\hline Oprk1-R & 5'-GTGCCTCCAAGGACTATCGC-3' & \\
\hline Adcy1-F & 5'-CCGGAACATGGACCTCTACTAC-3' & 284 \\
\hline Adcy1-R & 5'-ATAGGTGGGAGGAGATGGACTG-3' & \\
\hline Adcy2-F & 5'-CCTGGGACCAGGTGTCATTC-3' & 412 \\
\hline Adcy2-R & 5'-CCTGCTITGGGTCCCTGTAG-3' & \\
\hline Adcy3-F & 5'-TACTTCAAAAGGCAGCGCCA-3' & 482 \\
\hline Adcy3-R & 5'-TTGGCCAGGATCTCCCTCAG-3' & \\
\hline Adcy4-F & 5'-TTGACCCAAAGCGGGCAG-3' & 248 \\
\hline Adcy4-R & 5'-GCACACAGCACAGTTGTCAG-3' & \\
\hline Adcy5-F & 5'-ACTTGGCCATCTCTCTGCAC-3' & 445 \\
\hline Adcy5-R & 5'-TGATTCTCCGCAGCCAACTT-3' & \\
\hline Adcy6-F & 5'-GCGGTGAGGGAGAATCACTG-3' & 163 \\
\hline Adcy6-R & 5'-TCACACCTGTTACCTCACGC-3' & \\
\hline Adcy7-F & 5'-GCAGGTAACAGGGTCGGAG-3' & 392 \\
\hline Adcy7-R & 5'-AGGTCCTCAGCTCTTTGCAC-3' & \\
\hline Adcy8-F & 5'-TTGCGGAGTGGCGATAAGTT-3' & 482 \\
\hline Adcy8-R & 5'-ACAAAGTACTCTGGGTAGGAGC-3' & \\
\hline Adcy9-F & 5'-AAGACCAGCACCAAGGCTTC-3' & 183 \\
\hline Adcy9-R & 5'-GTTCTTGAACCTGAGCGGGA-3' & \\
\hline Bdnf-F & 5'-TGGCTGACACTITGAGCACGTC-3' & 135 \\
\hline Bdnf-R & 5'-GCTCCAAAGGCACTTGACTGCTGA-3' & \\
\hline Fos- F & 5'-GGTGAAGACCGTGTCAGGAGGCAG-3' & 117 \\
\hline Fos-R & 5'-GCCATCTTATTCCGTTCCCTTCGG-3' & \\
\hline Creb1-F & 5'-TACCCAGGGAGGAGCAATAC-3' & 183 \\
\hline Creb1-R & 5'-GAGGCAGCTTGAACAACAAC-3' & \\
\hline Dr1-F & 5'-TCGGCAGACATGTTGTGAGG-3' & 268 \\
\hline Dr1-R & 5'-TCTAGGGACACCACTCCCAG-3' & \\
\hline Egr1-F & 5'-GAGCACCTGACCACAGAGTC-3' & 172 \\
\hline Egr1-R & 5'-AAAGGGGTTCAGGCCACAAA-3' & \\
\hline$p 38 \alpha-\mathrm{F}$ & 5'-CACAGGGACCTAAAGCCCAG-3' & 305 \\
\hline$p 38 \alpha-R$ & 5'-TTCTTCAGAAGCTCAGCCCC-3' & \\
\hline Stat2-F & 5'-GTCCTTGAACCGCTTGGAGA-3' & 87 \\
\hline Stat2-R & 5'-TGCGCCATTTGGACTCTTCT-3' & \\
\hline 36B4-F & 5'-CGACCTGGAAGTCCAACTAC-3' & 109 \\
\hline 36B4-R & 5'-ATCTGCTGCATCTGCTTG-3' & \\
\hline
\end{tabular}

$F$, forward; $R$, reverse.

visualized using an automatic multifunction chemiluminescent detection system (Tanon, Shanghai, China). The signals were calculated by densitometry using Image software.

\section{Open Field Test}

The open field test was conducted in a sound-attenuated room using the universal spontaneous activity video analysis system (model no. JLBehv-LM4; Shanghai Jiliang Software Technology Co., Ltd., Shanghai, China) according to the previous report (Lv S. et al., 2020). The mouse was individually placed in the center of the apparatus, consisting of a square area surrounded by high walls $(25 \times 25 \times 31 \mathrm{~cm})$, which was equipped with a video camera above the center. The total distance traveled, velocity, and numbers of spontaneous activity were recorded. Mice were put in the apparatus for 30 min habituation after i.v. injection of saline or (pyr)apelin-13 or saline, and then immediately i.pl. injected with $1.0 \%$ formalin solution and put back in the apparatus again to test for $30 \mathrm{~min}$. The apparatus was cleaned with a $10 \%$ ethanol solution after each trial. The mice were divided into four groups: saline $(n=11)$ and (pyr)apelin-13 $(2 \mathrm{mg} / \mathrm{kg}, n=10 ; 10 \mathrm{mg} / \mathrm{kg}$, $n=9 ; 20 \mathrm{mg} / \mathrm{kg}, n=10)$.

\section{Wire Hanging Test}

The wire hanging test was conducted following the previous report (Niimi et al., 2009). The animal was placed on a stainless steel bar $(50 \mathrm{~cm}$ in length, $2 \mathrm{~mm}$ diameter, $37 \mathrm{~cm}$ above the floor) at a point midway between the supports and observed for $30 \mathrm{~s}$. The score was evaluated according to the following scheme: 0 , fell off; 1 , hung onto the wire by two forepaws; 2 , hung onto the wire by two forepaws, but also attempted to climb onto the wire; 3 , hung onto the wire by two forepaws plus one or both hindpaws around the wire; 4, hung onto the wire by all four paws plus tail wrapped; 5, escaped. Latency to falling off and the score were also recorded, and the cutoff latency was set at $30 \mathrm{~s}$. Each mouse had three opportunities, and the inter-trial intervals were $30 \mathrm{~min}$. Thirty minutes after saline or (pyr)apelin-13 treatment, formalin was i.pl. injected. After $15 \mathrm{~min}$, the wire hanging test was started. The mice were divided into four groups: saline and (pyr)apelin-13 (2, 10, and $20 \mathrm{mg} / \mathrm{kg}$, $n=10$ per group).

\section{Light/Dark Aversion Test}

The test was performed following De Angelis and Furlan (2000). The apparatus consisted of two compartments $(27 \times 21 \times 14 \mathrm{~cm})$, separated by a connecting gate $(7 \times 10 \mathrm{~cm})$. One of these compartments was darkened by black paint and covered with a black cover. The other compartment was lit by a $60-\mathrm{W}$ desk lamp $30 \mathrm{~cm}$ above. Each mouse was individually placed at the center of the bright compartment (facing away from the door). The total time spent in the light area and number of transitions between light and dark areas were measured for $5 \mathrm{~min}$. Thirty minutes after saline or (pyr)apelin-13 injection, formalin was i.pl. injected. After $15 \mathrm{~min}$, the light/dark aversion test was started. The mice were divided into four groups: saline $(n=10)$ and (pyr)apelin-13 $(2,10$, and $20 \mathrm{mg} / \mathrm{kg}, n=9$ per group).

\section{Statistical Analysis}

Data are presented as means \pm SEM. Analysis was performed by one-way ANOVA, followed by Dunnett's test for multiple comparisons using SPSS 16.0. The unpaired $t$-test was used to test 
the difference between the two groups. A $p<0.05$ was used as the criterion for statistical significance.

\section{RESULTS}

\section{The Effect of Peripheral (Pyr)Apelin-13 on the Nociceptive Response During the Mouse Formalin Test}

One-way ANOVA demonstrated i.v. administration of (pyr)apelin-13 (2, 10, and $20 \mathrm{mg} / \mathrm{kg})$ to have no influence on licking/biting time during the first phase $[F(3,31)=0.441$, $p=0.725]$ (Figure 1A). However, i.v. administration of (pyr)apelin-13 produced a dose-dependent decrease in licking/biting time during the second phase $[F(3,31)=6.350$, $p<0.01$ ] (Figure 1B). Compared with the control, (pyr)apelin13 significantly decreased the licking/biting time at doses of $10 \mathrm{mg} / \mathrm{kg}(p<0.05)$ and $20 \mathrm{mg} / \mathrm{kg}(p<0.01)$.

Administration of apelin-13 (non-pyroglutamyl) markedly reduced licking/biting time during the first phase of the formalin test only at the $10 \mathrm{mg} / \mathrm{kg}$ dose $(p<0.05$, Figure 1C) when compared with the control group. In the second phase, apelin13 had no obvious influence on licking/biting time $(2 \mathrm{mg} / \mathrm{kg}$, $p=0.919 ; 10 \mathrm{mg} / \mathrm{kg}, p=0.216 ; 20 \mathrm{mg} / \mathrm{kg}, p=0.124$; Figure 1D), compared with the control.

Injection (i.m.) of (pyr)apelin-13 (10 and $20 \mathrm{mg} / \mathrm{kg}$ ) had no effect on paw licking/biting time during the first phase, compared with saline treatment $(p=0.452, p=0.800$, Figure 1E). During the second phase, i.m. administration of (pyr)apelin-13 produced a significant decrease in licking/biting time at $20 \mathrm{mg} / \mathrm{kg}(p<0.05)$, not at $10 \mathrm{mg} / \mathrm{kg}(p=0.998$, Figure 1F).

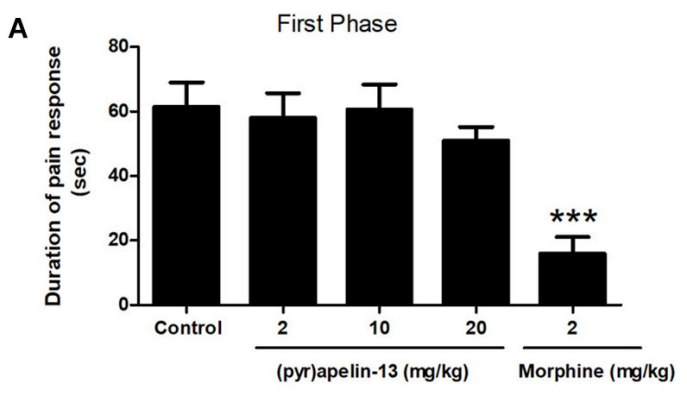

B

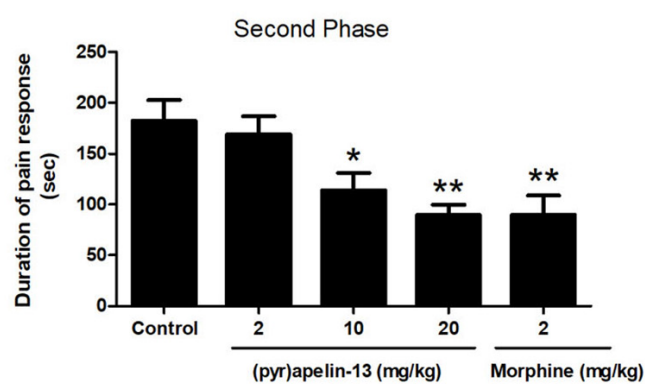

C

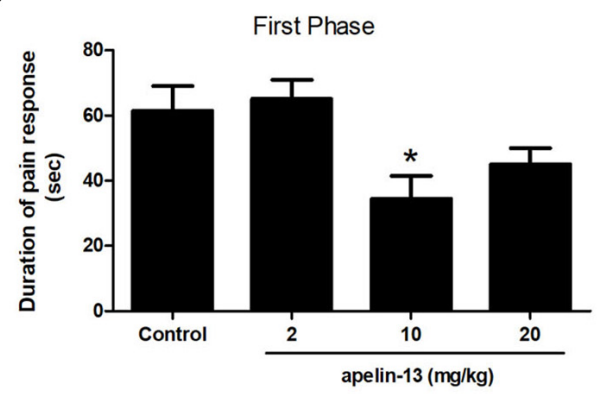

E

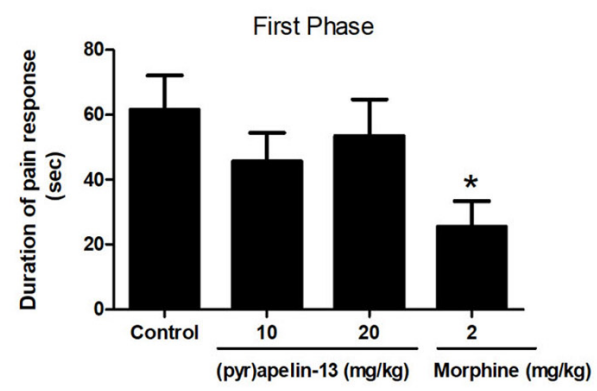

D

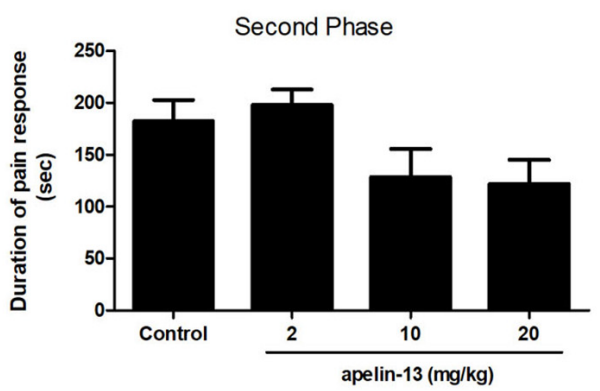

F

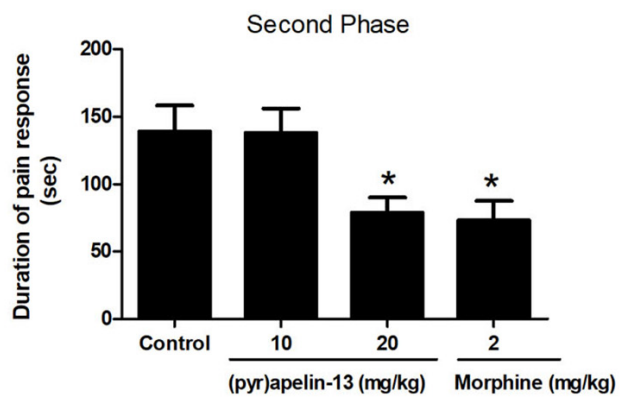

FIGURE 1 | Antinociception by (pyr)apelin-13 and apelin-13 during the formalin test. (A,B) Normal saline (control), (pyr)apelin-13 (2, 10, 20 mg/kg), or morphine (2 mg/kg) were intravenously (i.v.) injected 30 min before intraplantar (i.pl.) injection of formalin. (C,D) Normal saline, apelin-13 (2, 10, 20 mg/kg), or morphine (2 mg/kg) were i.v. administered before i.pl. injection of formalin. (E,F) Normal saline, (pyr)apelin-13 (10, $20 \mathrm{mg} / \mathrm{kg}$ ), or morphine (2 mg/kg) were i.m. administrated before i.pl. injection of formalin. Each point is the mean licking/biting time during the early phase (0-10 min) or late phase (10-30 min) of the formalin test. Data are expressed as means \pm SEM. $n=7-10$ per group. ${ }^{*} p<0.05,{ }^{* *} p<0.01$, and ${ }^{* \star *} p<0.001$ vs. control according to ANOVA followed by Dunnett's test. 

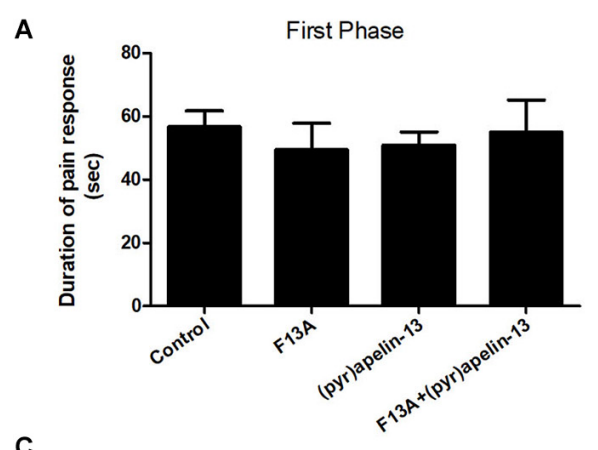

B
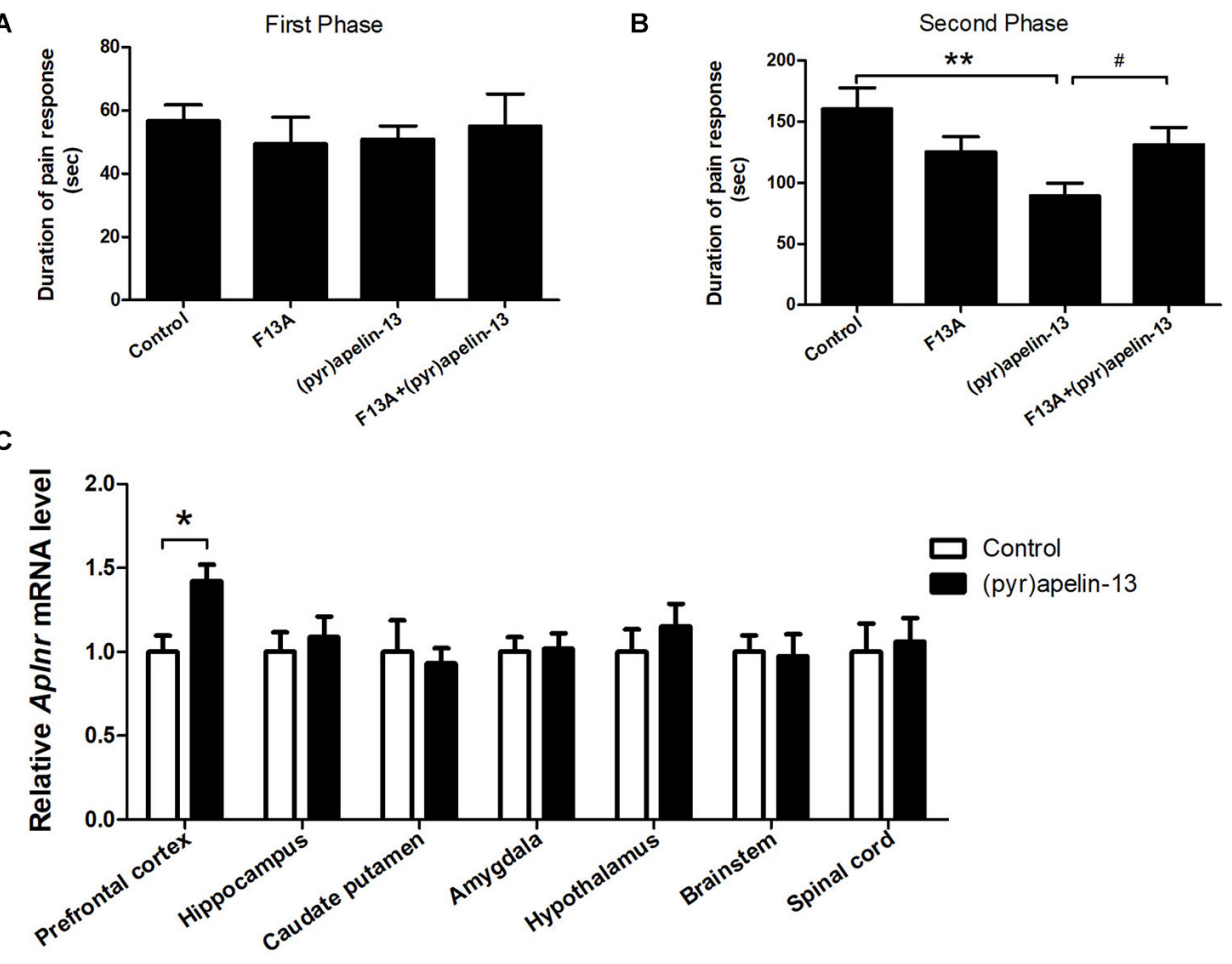

D

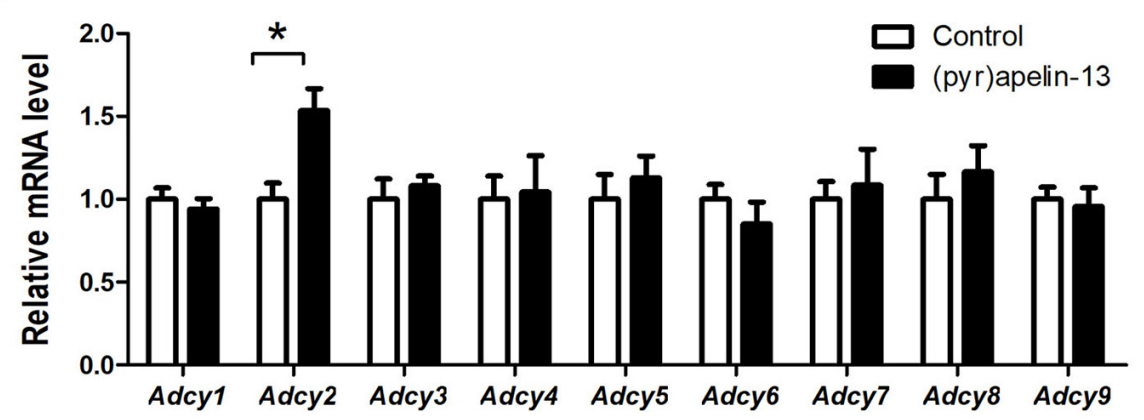

E

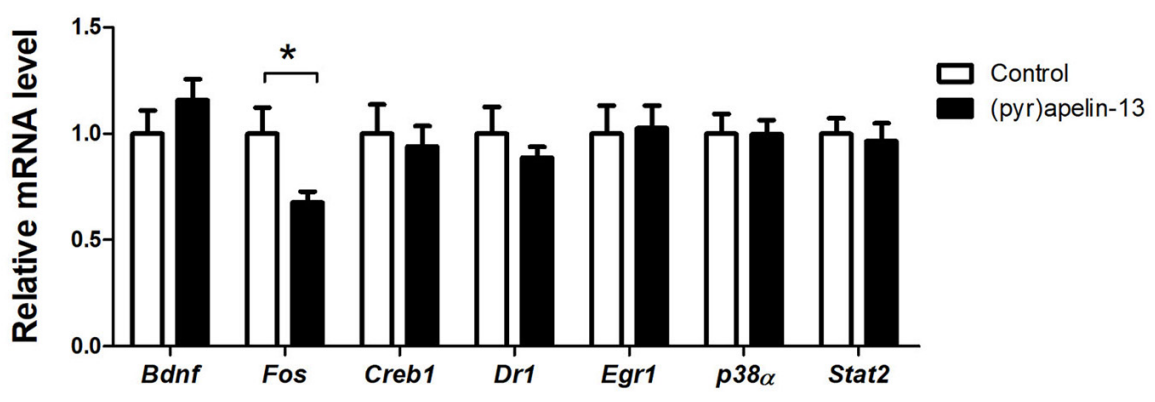

FIGURE 2 | The effect of an APJ antagonist on the antinociception of (pyr)apelin-13, the influence of i.v. (pyr)apelin-13 on APJ gene expression in different brain regions, as well as Adcy1-Adcy9 gene expression in the prefrontal cortex. (A,B) The effect of an APJ antagonist on apelin-13(F13A) $(20 \mathrm{mg} / \mathrm{kg}$, i.v.) and the antinociception of (pyr)apelin-13 (20 mg/kg, i.v.) in the formalin test. The apelin-13(F13A) was i.v. co-administrated with (pyr)apelin-13. The data were analyzed by ANOVA followed by Dunnett's test. (C) The effect of (pyr)apelin-13 $(20 \mathrm{mg} / \mathrm{kg}$, i.v.) on APJ mRNA levels in the prefrontal cortex, hippocampus, caudate putamen, amygdala, hypothalamus, brainstem, and spinal cord. (D) The effect of (pyr)apelin-13 on Adcy1, Adcy2, Adcy3, Adcy4, Adcy5, Adcy6, Adcy7, Adcy8, and Adcy9 mRNA levels in the mouse prefrontal cortex. (E) The effect of (pyr)apelin-13 on Bdnf, Fos, Creb1, Dr1, Egr1, p38 $\alpha$, and Stat2 mRNA level in the mouse prefrontal cortex. The unpaired t-test was performed to test the difference between (pyr)apelin and the control group (C-E). Data are expressed as means \pm SEM. $n=8-10$ per group. ${ }^{*} p<0.05,{ }^{* *} p<0.01$ vs. control; ${ }^{\#} p<0.05$ vs. (pyr)apelin- 13 treated group. 


\section{The Effect of i.v. (Pyr)Apelin-13 on APJ}

To determine whether the APJ receptor mediated the antinociception effect of i.v. (pyr)apelin-13, the APJ receptor antagonist, apelin-13(F13A), was administered and Aplnr mRNA was assessed in different mouse brain regions. Apelin-13(F13A) (20 mg/kg) alone had no influence on licking/biting time in either phase $1(p=0.442$, Figure $2 \mathrm{~A})$ or phase $2(p=0.137$, Figure 2B) during the formalin test. However, co-administration (i.v.) of apelin-13(F13A) (20 mg/kg) with (pyr)apelin-13 $(20 \mathrm{mg} / \mathrm{kg}$ ) significantly blocked the antinociceptive effect of (pyr)apelin-13 during phase $2(p<0.05$, Figure 2B). Moreover, i.v. administration of (pyr)apelin-13 significantly upregulated Aplnr gene expression only in the mouse prefrontal cortex $(p<0.01)$, but not in the hippocampus $(p=0.613)$, caudate putamen $(p=0.742)$, amygdala $(p=0.898)$, hypothalamus $(p=0.435)$, brainstem $(p=0.869)$, or spinal cord $(p=0.783)$, compared with the control (Figure 2C).

\section{The Effect of i.v. Administration of (Pyr)Apelin-13 on Gene Expression}

To explore the potential signals involved in the antinociception of (pyr)apelin-13, the G protein-coupled receptor APJ's downstream genes Adcy1-Adcy9, Bdnf, Fos, Creb1, and others were assessed in the prefrontal cortex. (pyr)Apelin-13 significantly upregulated gene expression of Adcy2 $(p<0.05)$, but not the other Adcys (Figure 2D). (pyr)Apelin-13 obviously downregulated Fos gene expression $(p<0.05)$. However, (pyr)apelin-13 had no influence on the expression of Bdnf, Creb1, Dr1, Egr1, p38 $\alpha$, or Stat2 (Figure 2E).

\section{The Effect of Naloxone and Nor-BNI on the Antinociception Effect of i.v. Administered (Pyr)Apelin-13}

To further investigate the involvement of the opioid receptors in the antinociceptive effect of (pyr)apelin-13, the non-specific opioid receptor antagonist naloxone and the specific KOR antagonist nor-BNI were evaluated. Naloxone $(2 \mathrm{mg} / \mathrm{kg})$ had no effect on licking/biting during the first $(p=0.312)$ or the second phase $(p=0.591)$ of the formalin test, when compared with the control (Figures 3A,B). However, i.v. co-administration of naloxone markedly reversed the antinociceptive response induced by (pyr)apelin-13 (20 mg/kg) during the second phase of the formalin test $(p<0.01$, Figure 3B). As shown in Figures 3C,D, compared with saline treatment, norBNI $(10 \mathrm{mg} / \mathrm{kg})$ had no influence on the formalin-induced nociceptive behavior during the first $(p=0.980)$ or the second phase $(p=0.188)$. However, co-administration of nor-BNI significantly antagonized the analgesic effect of (pyr)apelin-13

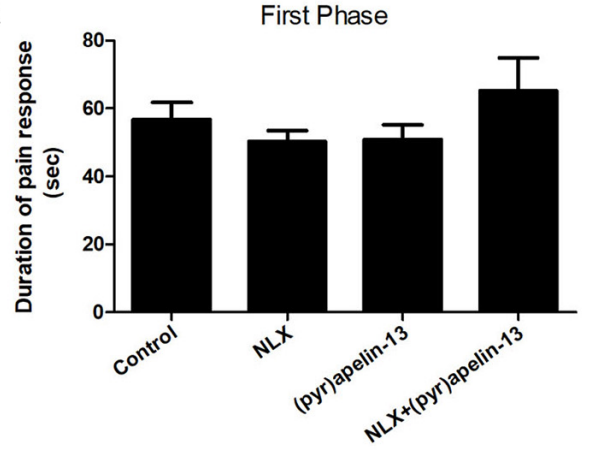

C

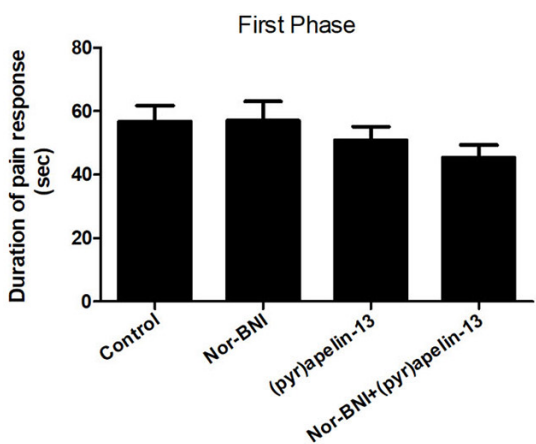

B
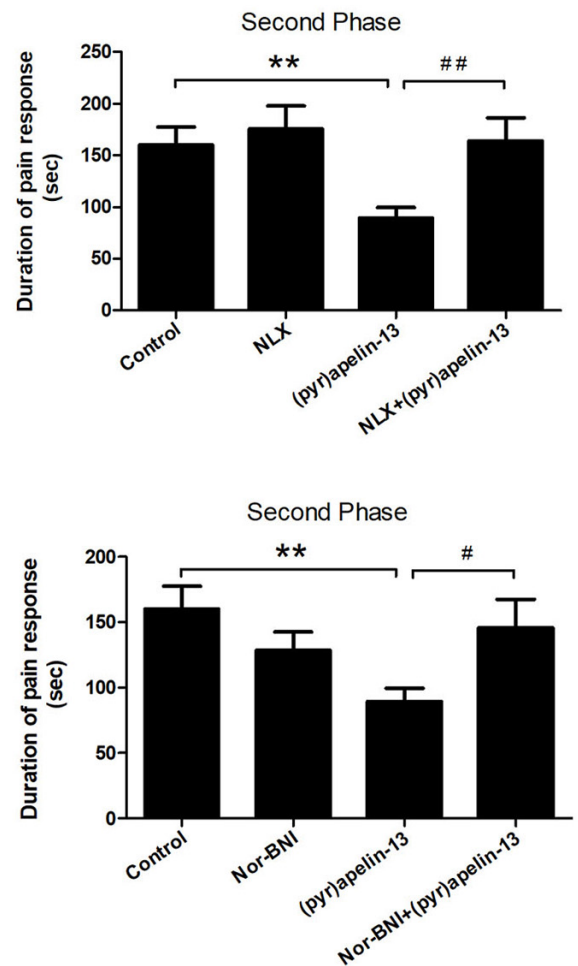

FIGURE 3 | The effect of opioid receptor antagonists on the antinociception of (pyr)apelin-13. (A,B) The influence of non-selective opioid receptor antagonist naloxone (NLX, $2 \mathrm{mg} / \mathrm{kg})$ on the antinociceptive effect induced by (pyr)apelin-13 $(20 \mathrm{mg} / \mathrm{kg})$ in the formalin test. (C,D) The influence of selective KOR antagonist, nor-Binaltorphimine (nor-BNI, $10 \mathrm{mg} / \mathrm{kg}$ ), on the antinociceptive effect induced by (pyr)apelin-13 in the formalin test. The NLX or nor-BNI was i.v. co-administrated with (pyr)apelin-13, respectively. Values are presented as means \pm SEM. $n=7-10 /$ group. ${ }^{* *} p<0.01$ vs. control; ${ }^{\#} p<0.05$ and ${ }^{\# \#} p<0.01$ vs. (pyr)apelin-13 treated group. 
(20 $\mathrm{mg} / \mathrm{kg}$ ) during the second phase of the formalin test $(p<0.01$, Figure 3D).

\section{The Effect of (Pyr)Apelin-13 on Gene Expression and Levels of Endogenous Opioid Peptides and Opioid Receptors}

To determine which endogenous opioid peptides were involved in the antinociception effect of (pyr)apelin-13, the mRNAs level of Pomc, Penk, and Pdyn in the prefrontal cortex were determined. As shown in Figure 4A, i.v. administration of (pyr)apelin-13 did not influence Pomc $(p=0.437)$ or Penk $(p=0.912)$ expression compared with saline treatment. However, $P d y n$ expression was significantly upregulated $(p<0.05)$. To identify which type of opioid receptor participated in the analgesic effect of (pyr)apelin-13, the expression levels of Oprm1, Oprd1, and Oprk1 were analyzed. Neither Oprm1 $(p=0.796)$ nor
Oprd1 ( $p=0.808)$ expression levels were changed by (pyr)apelin13, compared with the control (Figure 4B). In contrast, Oprk1 gene expression was obviously increased $(p<0.05)$. ELISA found that (pyr)apelin-13 significantly upregulated the levels of dynorphin in the prefrontal cortex $(p<0.05$, Figure 4C), but not in the serum, when compared with the control $(p=0.596$, Figure 4D). Western blot analysis demonstrated the protein level of the KOR to be significantly increased in the prefrontal cortex in animals treated with (pyr)apelin-13-treated, compared with the control $(p<0.05$, Figures 4E,F).

To explore whether (pyr)apelin-13 has an influence on dynorphin/KOR in striatum, the mRNA and protein levels of dynorphin/KOR were detected. As shown in Figures $\mathbf{5 A}, \mathbf{B}$, (pyr)apelin-13 did not produce a significant influence on Pomc ( $p=0.683)$, Penk $(p=0.640)$, Pdyn $(p=758)$, Oprm1 $(p=0.985)$, Oprd1 $(p=0.576)$, or Oprk1 $(p=0.962)$ in striatum, compared with the saline-treated group. ELISA and western blot results
A

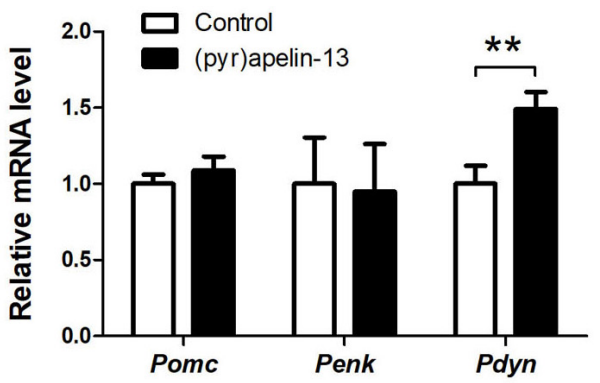

C

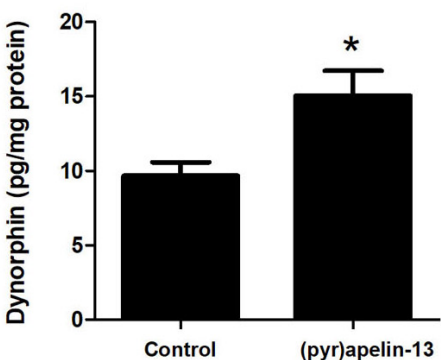

$E$

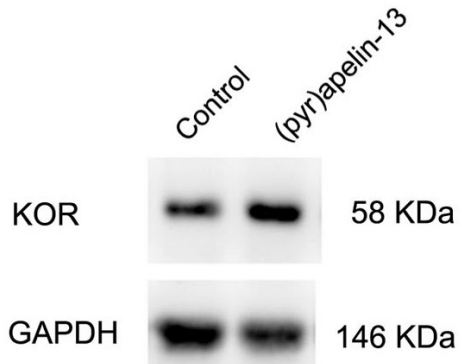

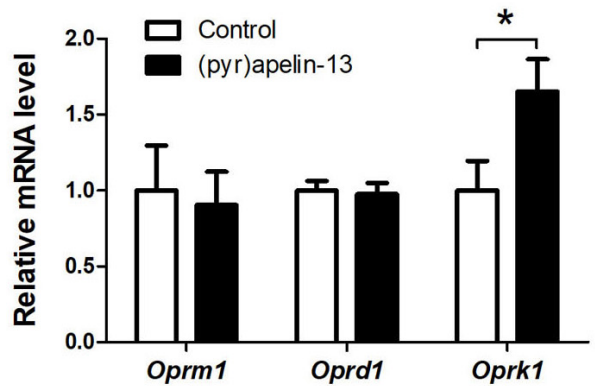

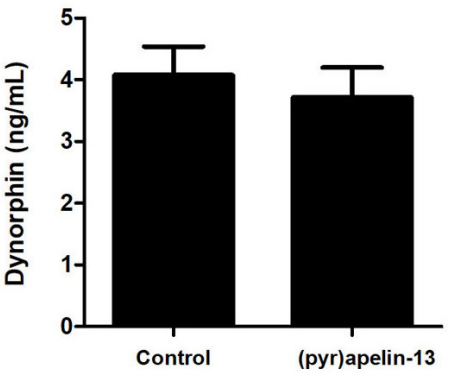

$\mathbf{F}$

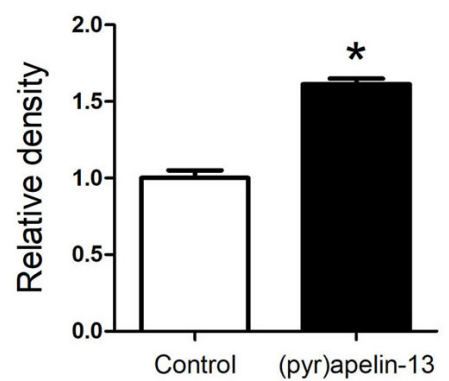

FIGURE 4 | The effect of (pyr)apelin-13 on endogenous opioid peptides, opioid receptor gene and protein expression, and the content of dynorphin in the prefrontal cortex or serum in mice. (A,B) The effect of (pyr)apelin-13 (20 mg/kg, i.v.) on the relative mRNA levels of Pomc, Penk, Pdyn, Oprm1, Oprd1, and Oprk1 normalized to the housekeeping gene 36B4 mRNA levels by real-time PCR. The concentration of dynorphin in the prefrontal cortex (C) and serum (D) was assessed by ELISA. Representative western blot (E) and relative protein levels (F) of the KOR, normalized to the housekeeping protein GAPDH. Data are presented as means \pm SEM. The difference between (pyr)apelin-13 and the control group was analyzed by the unpaired $t$-test. $n=5-8 /$ group. ${ }^{*} p<0.05$ and ${ }^{* *} p<0.01$ vs. control. 
A

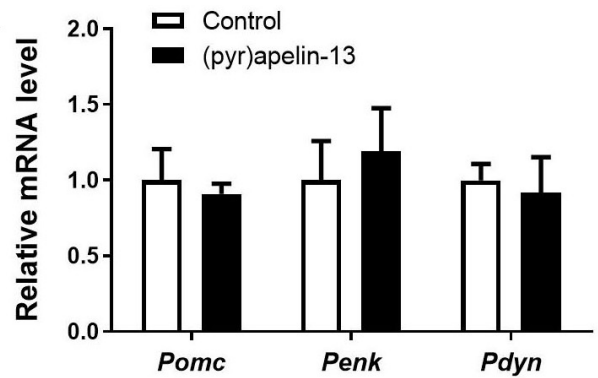

C

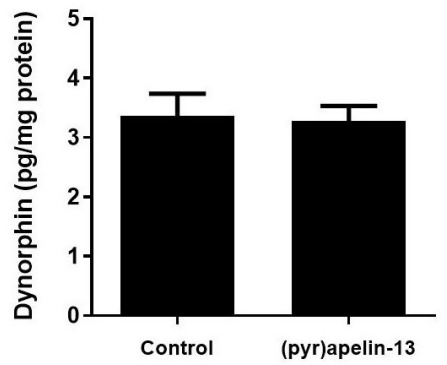

B

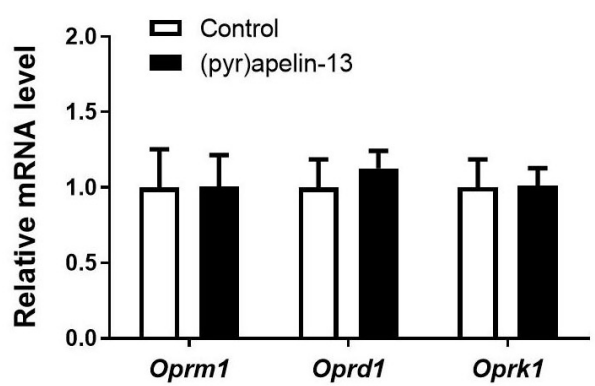

D

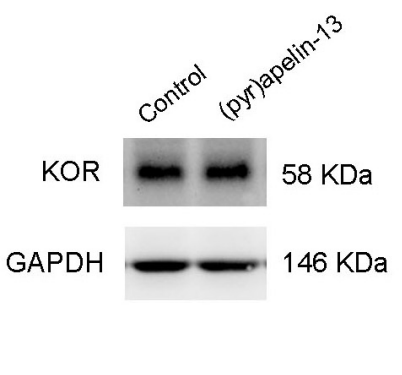

E

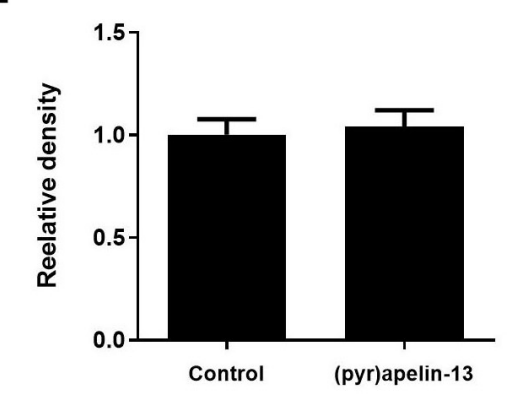

FIGURE 5 | The influence of (pyr)apelin-13 on endogenous opioid peptides, opioid receptor gene and protein expression, and the content of dynorphin in the striatum in mice. (A,B) The effect of (pyr)apelin-13 (20 mg/kg, i.v.) on the relative mRNA levels of Pomc, Penk, Pdyn, Oprm1, Oprd1, and Oprk1 in striatum. They were normalized to the housekeeping gene $36 B 4$ mRNA levels by real-time PCR. The concentration of dynorphin in the striatum (C) was assessed by ELISA. Representative western blot (D) and relative protein levels (E) of the KOR, normalized to the housekeeping protein GAPDH. The unpaired t-test was performed to compare the difference between the (pyr)apelin-13-treated group and control. Data are presented as means \pm SEM. $n=6-10 /$ group.

demonstrated that (pyr)apelin-13 did change the content of dynorphin ( $p=0.854$, Figure $5 \mathrm{C}$ ) or KOR expression $(p=0.725$, Figures 5D,E) in striatum, compared with the control.

\section{The Effect of (Pyr)Apelin-13 on Motor Function and Light/Dark Aversion}

To examine whether (pyr)apelin-13 could induce side effects of motor impairment and aversion during the process of antinociception, we detect the related indexes using the open field test, wire hanging test, and light/dark aversion test. Intravenous administration of (pyr)apelin-13 (2, 10, and $20 \mathrm{mg} / \mathrm{kg})$ had no influence on total distance traveled $[F(3,36)=0.201$, $p=0.895]$, average velocity $[F(3,36)=0.201, p=0.895]$, or spontaneous activity $[F(3,31)=0.658, p=0.583]$ in the open field test (Table 2). (pyr)Apelin-13 (2, 10, and $20 \mathrm{mg} / \mathrm{kg}$ ) did not change the score $[F(3,36)=0.326, p=0.807]$ or latency $[F(3,36)=0.186, p=0.905]$ in the wire hanging test (Table 3). In the light/dark aversion, (pyr)apelin-13 $(2,10$, and $20 \mathrm{mg} / \mathrm{kg})$ had no effect on the number of transitions $[F(3$, $33)=0.290, p=0.832]$ or time (s) lit area $[F(3,33)=0.792$, $p=0.507$, Table 4].

\section{DISCUSSION}

This study demonstrated that i.v. or i.m. injection of (pyr)apelin13 or apelin-13 produced an antinociceptive effect in a murine formalin-induced paw inflammatory pain model.
The antinociception of i.v. (pyr)apelin-13 was significantly antagonized by antagonist for the APJ receptor, the opioid receptor, and the KOR. (pyr)Apelin-13 (i.v., $20 \mathrm{mg} / \mathrm{kg}$ ) upregulated $A p \ln r$ and $A d c y 2$ gene expression and downregulated Fos gene expression in the prefrontal cortex of the mice. Also, (pyr)apelin-13 produced an increase in the mRNA and protein levels of dynorphin and KOR in the prefrontal cortex, not striatum. In addition, (pyr)apelin-13 did produce side effects of motor impairment and aversion during the process of antinociception.

The formalin test is a model of tonic continuous pain induced by injured tissue and is a valid model for clinical pain (Tjolsen et al., 1992). This model is typically used to evaluate the tonic analgesic effect of pharmacological agents in that the model is reproducible and provides a quantifiable behavioral response (Reeta et al., 2006). Our results demonstrated a characteristic biphasic pain response induced by $1 \%$ formalin in the mouse hind paw, similar to previous reports (Tjolsen et al., 1992; Abbadie et al., 1997). The first phase $(0-10 \mathrm{~min})$ is produced by direct activation of nociceptive neurons by formalin, with the second phase (10-30 $\mathrm{min}$ ) due to an inflammatory response to tissue injury (Abbott et al., 1995). This study demonstrated (pyr)apelin13 (10 and $20 \mathrm{mg} / \mathrm{kg}$, i.v.) to inhibit pain behavior during the second phase, but not during the first phase of the formalin test. Apelin-13 (10 mg/kg, i.v.) produced an antinociceptive effect during the first phase, but not the second phase of the formalin test. These observations may be due to characteristics (such as stability, degradation) of the different molecular forms 
TABLE 2 | Effect of (pyr)apelin-13 on open field test in mice.

\begin{tabular}{|c|c|c|c|c|c|}
\hline Treatment & Dose (mg/kg) & $n$ & Total distance traveled $(\mathrm{mm})$ & Average velocity $(\mathrm{mm} / \mathrm{s})$ & Spontaneous activity (n) \\
\hline Vehicle & - & 11 & $15939.11 \pm 2229.23$ & $8.85 \pm 1.24$ & $281.18 \pm 13.80$ \\
\hline (pyr)Apelin-13 & 2 & 10 & $16044.83 \pm 4131.48$ & $8.91 \pm 2.30$ & $245.40 \pm 21.63$ \\
\hline (pyr)Apelin-13 & 10 & 9 & $12940.84 \pm 1762.58$ & $7.19 \pm 0.98$ & $259.33 \pm 19.98$ \\
\hline (pyr)Apelin-13 & 20 & 10 & $14557.33 \pm 3818.45$ & $8.09 \pm 2.12$ & $248.00 \pm 26.40$ \\
\hline
\end{tabular}

ANOVA was used to compare the difference between (pyr)apelin-13 and vehicle.

of apelin-13. Further, (pyr)apelin-13 (20 mg/kg, i.m.) produced an antinociceptive response during the second phase of the formalin test, not the first. These results demonstrate peripheral (pyr)apelin-13 to mitigate inflammatory pain. The discrepancy results of (pyr)apelin-13 in the first phase and the second phase of the formalin test may be due to their different modulatory mechanisms of the two phases. The first phase was caused by a bursting activity from pain fibers, such as $\mathrm{C}$ fibers, whereas the second phase was caused by inflammation and central sensitization (Tjolsen et al., 1992; McNamara et al., 2007).

Apelin is an endogenous ligand for APJ, which is a seventransmembrane GPCR (Tatemoto et al., 1998). Apelin-13(F13A) is a specific antagonist of the apelin receptor and has been used to explore the mechanistic basis for the hypotensive effect induced by apelin-13 (Lee et al., 2005). Our results demonstrate apelin13(F13A) to significantly block the antinociceptive effect of i.v. (pyr)apelin-13 during the second phase of the mouse formalin test, suggesting the involvement of APJ in the antinociception induced by i.v. administration of (pyr)apelin-13. These results are in accordance with a previous report in which APJ was shown to be involved in the antinociception of apelin-13 in a mouse visceral pain model (Lv et al., 2012).

The prefrontal cortex is important for pain processing (Ong et al., 2019). By meta-analysis of experimental pain studies, Apkarian et al. (2005) concluded that the prefrontal cortex, anterior cingulate cortex, insular cortex, and other regions of

TABLE 3 | Effect of (pyr)apelin-13 on the wire hanging test in mice.

\begin{tabular}{lcccc}
\hline Treatment & Dose (mg/kg) & $\boldsymbol{n}$ & Score & Latency (s) \\
\hline Vehicle & - & 10 & $3.53 \pm 0.43$ & $11.50 \pm 1.78$ \\
(pyr)Apelin-13 & 2 & 10 & $3.63 \pm 0.39$ & $13.33 \pm 2.51$ \\
(pyr)Apelin-13 & 10 & 10 & $3.73 \pm 0.38$ & $12.90 \pm 1.71$ \\
(pyr)Apelin-13 & 20 & 10 & $4.03 \pm 0.30$ & $13.57 \pm 2.45$
\end{tabular}

ANOVA was used to compare the difference between (pyr)apelin-13 and vehicle.

TABLE 4 | Effect of (pyr)apelin-13 in the light/dark aversion test in mice.

\begin{tabular}{lcccc}
\hline Treatment & $\begin{array}{c}\text { Dose } \\
(\mathbf{m g} / \mathbf{k g})\end{array}$ & $\boldsymbol{n}$ & $\begin{array}{c}\text { Number of } \\
\text { transitions/5 } \mathbf{~ m i n}\end{array}$ & $\begin{array}{c}\text { Time (s) lit } \\
\text { area/5 } \mathbf{~ m i n}\end{array}$ \\
\hline Vehicle & - & 10 & $8.90 \pm 3.41$ & $244.20 \pm 23.85$ \\
(pyr)Apelin-13 & 2 & 9 & $10.44 \pm 3.79$ & $233.00 \pm 22.52$ \\
(pyr)Apelin-13 & 10 & 9 & $12.00 \pm 2.12$ & $224.67 \pm 18.25$ \\
(pyr)Apelin-13 & 20 & 9 & $8.00 \pm 3.34$ & $267.33 \pm 15.29$ \\
\hline
\end{tabular}

ANOVA was used to compare the difference between (pyr)apelin-13 and vehicle. the brain are positively associated with pain. Our results indicate that i.v. administration of (pyr)apelin-13 upregulated Aplnr gene expression in the mouse prefrontal cortex, but not in the hippocampus, caudate putamen, amygdala, hypothalamus, brainstem, or spinal cord. Hence, the effect of peripheral (pyr)apelin-13 is on the brain, especially within the prefrontal cortex, during inflammatory pain.

Adenylate cyclase (ADCY) is APJ's downstream signaling molecule (Burghi et al., 2019). We found that i.v. administration of (pyr)apelin-13 upregulated Adcy2 gene expression in the prefrontal cortex of formalin-treated mice. Thus, (pyr)apelin13 likely exerts its antinociceptive effect by activating APJ/ADCY2. In addition, we found that Fos gene expression was downregulated by (pyr)apelin-13 in this formalin-induced inflammatory pain model. Fos is believed to be a neural marker of pain. Fos expression most likely reflects the role that the central nervous system plays in the stress response elicited by pain (Harris, 1998). Therefore, the inhibitory effect of (pyr)apelin-13 on inflammatory pain would be followed by a decrease in the pain marker, Fos.

Opioid systems play an important role in the modulation of pain behavior and antinociception. Our study demonstrated that the non-selective opioid receptor antagonist, naloxone, blocked the antinociception of (pyr)apelin-13 during the second phase of the formalin test, suggesting the involvement of the opioid receptor in the inhibitory effect of (pyr)apelin13 on inflammatory pain. The classified receptor subtypes include $\mathrm{mu}(\mu)$, kappa $(\kappa)$, and delta $(\delta)$ opioid receptors. The corresponding precursors of these endogenous opioid peptides

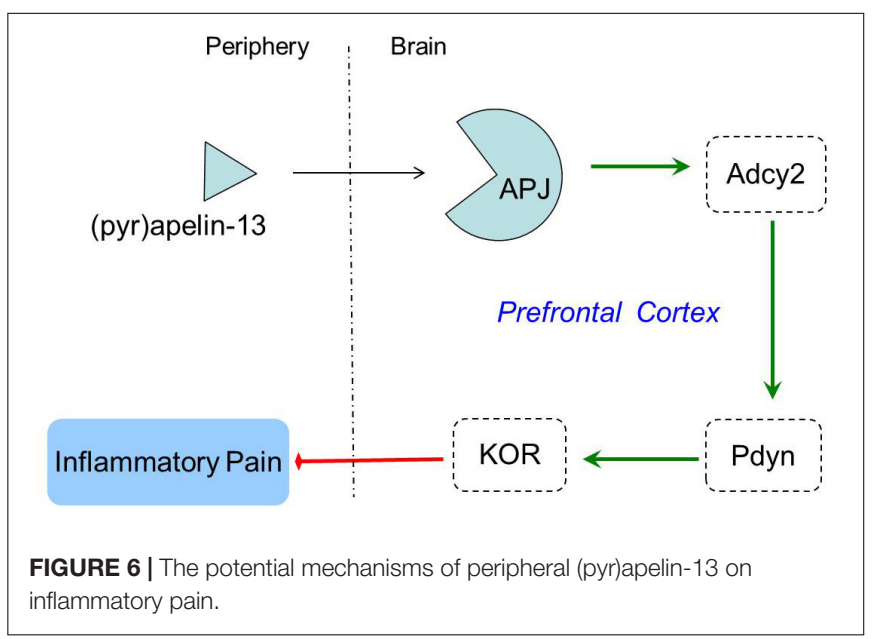


are proopiomelanocortin (POMC), prodynorphin (PDYN), and preproenkephalin (PENK). Recent studies indicated that APJ formed a heterodimer with $\mathrm{KOR}$, suggesting a close relationship between apelin/APJ system and KOR ( $\mathrm{Li}$ et al., 2012; Rostamzadeh et al., 2017). We found i.v. (pyr)apelin13 to significantly upregulate $P d y n$ and Oprk1 gene expression in the mouse prefrontal cortex, but not Pomc, Penk, Oprm1, or Oprd1. Moreover, we found dynorphin and KOR levels in the prefrontal cortex to be significantly increased as judged by ELISA and western blot analysis. Intriguingly, similar variations in transcript and protein levels of PDYN and KOR indicated that the antinociception of (pyr)apelin-13 may be mediated by the PDYN/KOR system. In addition, the KOR antagonist, nor-BNI, antagonized the antinociceptive effect induced by (pyr)apelin-13 during the second phase of the formalin test, which confirms the involvement of KOR. This result is supported by previous reports that the release of dynorphin plays a role in the control of inflammatory pain (Cabot et al., 2001) and that $\mathrm{KOR}$ is involved in regulation of nociceptive behaviors in a variety of animal pain models (Kivell and Prisinzano, 2010). Striatum played an important role in pain modulation (Barcelo et al., 2012). Unfortunately, we found that (pyr)apelin13 did not influence PDYN/KOR gene or protein expression in striatum. Based on these results, we speculated that i.v. injection of (pyr)apelin-13 induced an increase of (pyr)apelin-13 in brain, activated the APJ in prefrontal cortex first, stimulated Adcy 2 gene expression, and then exerted the dynorphin/KOR, thereby exhibiting an antinociceptive effect against inflammatory pain (as shown in Figure 6). Some analgesics were commonly accompanied by side effects (Meymandi et al., 2006). Our present study demonstrated that (pyr)apelin-13 did not influence motor function and light/dark aversion, suggesting a potential analgesic compound for (pyr)apelin-13.

\section{CONCLUSION}

In summary, the peripheral administration of (pyr)apelin-13 produced an antinociceptive effect during the inflammatory phase (second phase) of the mouse formalin test. The antinociception of (pyr)apelin-13 was mediated through the APJ receptor, which activated the endogenous dynorphin/KOR

\section{REFERENCES}

Abbadie, C., Taylor, B. K., Peterson, M. A., and Basbaum, A. I. (1997). Differential contribution of the two phases of the formalin test to the pattern of $\mathrm{c}$-fos expression in the rat spinal cord: studies with remifentanil and lidocaine. Pain 69, 101-110. doi: 10.1016/s0304-3959(96)03 285-x

Abbott, F. V., Franklin, K. B., and Westbrook, R. F. (1995). The formalin test: scoring properties of the first and second phases of the pain response in rats. Pain 60, 91-102. doi: 10.1016/0304-3959(94)00 095-v

Acar, N., Parlak, H., Ozkan, A., Soylu, H., Avcl, S., Ustunel, I., et al. (2019). The effect of docosahexaenoic acid on apelin distribution of nervous system in the experimental mouse model of Parkinson's disease. Tissue Cell 56, 41-51. doi: 10.1016/j.tice.2018.12.002 system in the prefrontal cortex of mice. This study may pave the way for a new strategy for the investigation and control of inflammatory pain.

\section{DATA AVAILABILITY STATEMENT}

The raw data supporting the conclusions of this article will be made available by the authors, without undue reservation, to any qualified researcher.

\section{ETHICS STATEMENT}

The animal study was reviewed and approved by the Committee of Medical Ethics and Welfare for Experimental Animals, Henan University School of Medicine.

\section{AUTHOR CONTRIBUTIONS}

$\mathrm{YY}$ and XW developed the idea, designed the research, and contributed to revise the writing. SL, XZ, YF, YZ, and $\mathrm{BC}$ performed the experiment and analyzed the data. SL wrote the draft of the article. All authors contributed to the article and approved the submitted version.

\section{FUNDING}

This work was supported by the National Natural Science Foundation of China (Grant Nos. 81600974 and 81971280), the Key Science and Technology Program of Henan Province in China (Grant No. 192102310080), the Youth Talent Promotion Plan of Henan Association for Science and Technology (Grant No. 2020HYTP054), the Research Program for Young Talent of Henan University School of Medicine (Grant No. 2019018), the Key Science and Technology Program of Kaifeng City in China (Grant Nos. 1803034 and 1903019), the Key Scientific Research Program for Universities of Henan Province in China (Grant No. 17A310003) to SL, and the National Natural Science Foundation of China (Grant No. 81771307) to XW.

Apkarian, A. V., Bushnell, M. C., Treede, R. D., and Zubieta, J. K. (2005). Human brain mechanisms of pain perception and regulation in health and disease. Eur. J. Pain 9, 463-484. doi: 10.1016/j.ejpain.2004.11.001

Barcelo, A. C., Filippini, B., and Pazo, J. H. (2012). The Striatum and Pain Modulation. Cell Mol. Neurobiol. 32, 1-12. doi: 10.1007/s10571-011-9737-7

Burghi, V., Echeverria, E. B., Sosa, M. H., Quiroga, D. T., Munoz, M. C., Davio, C., et al. (2019). Participation of G alpha(i)-Adenylate Cyclase and ERK1/2 in Mas Receptor Signaling Pathways. Front. Pharmacol. 10:146. doi: 10.3389/fphar. 2019.00146

Cabot, P. J., Carter, L., Schafer, M., and Stein, C. (2001). Methionine-enkephalinand dynorphin A-release from immune cells and control of inflammatory pain. Pain 93, 207-212. doi: 10.1016/s0304-3959(01)00322-0

Chen, D., Lee, J., Gu, X., Wei, L., and Yu, S. P. (2015). Intranasal delivery of apelin13 Is neuroprotective and promotes angiogenesis after ischemic stroke in mice. ASN Neuro 7:1759091415605114. doi: 10.1177/1759091415605114 
Chen, F.-L., Li, J., Wang, B., Tian, S.-W., and Long, C. (2019). Apelin-13 enhances contextual fear extinction in rats. Neurosci. Lett. 712, 134487-134487. doi: 10. 1016/j.neulet.2019.134487

Dai, T.-T., Wang, B., Xiao, Z.-Y., You, Y., and Tian, S.-W. (2018). Apelin13 upregulates BDNF against chronic stress-induced depression-like phenotypes by ameliorating HPA axis and hippocampal glucocorticoid receptor dysfunctions. Neuroscience 390, 151-159. doi: 10.1016/j.neuroscience. 2018.08.018

De Angelis, L., and Furlan, C. (2000). The anxiolytic-like properties of two selective MAOIs, moclobemide and selegiline, in a standard and an enhanced light/dark aversion test. Pharmacol. Biochem. Behav. 65, 649-653. doi: 10.1016/s00913057(99)00237-3

Dubuisson, D., and Dennis, S. G. (1977). The formalin test: a quantitative study of the analgesic effects of morphine, meperidine, and brain stem stimulation in rats and cats. Pain 4, 161-174. doi: 10.1016/0304-3959(77)90130-0

Fan, J., Ding, L., Xia, D., Chen, D., Jiang, P., Ge, W., et al. (2017). Amelioration of apelin-13 in chronic normobaric hypoxia-induced anxiety-like behavior is associated with an inhibition of NF- $\mathrm{KB}$ in the hippocampus. Brain Res. Bull. 130, 67-74. doi: 10.1016/j.brainresbull.2017.01.005

Fan, J., Guang, H., Zhang, H., Chen, D., Ding, L., Fan, X., et al. (2018). SIRT1 mediates apelin-13 in ameliorating chronic normobaric hypoxia-induced anxiety-like behavior by suppressing NF- $\mathrm{KB}$ pathway in mice hippocampus. Neuroscience 381, 22-34. doi: 10.1016/j.neuroscience.2018.04.013

Gourdy, P., Cazals, L., Thalamas, C., Sommet, A., Calvas, F., Galitzky, M., et al. (2018). Apelin administration improves insulin sensitivity in overweight men during hyperinsulinaemic-euglycaemic clamp. Diabetes Obes. Metab. 20, 157164. doi: $10.1111 /$ dom. 13055

Habata, Y., Fujii, R., Hosoya, M., Fukusumi, S., Kawamata, Y., Hinuma, S., et al. (1999). Apelin, the natural ligand of the orphan receptor APJ, is abundantly secreted in the colostrum. Biochim. Biophys. Acta 1452, 25-35. doi: 10.1016/ s0167-4889(99)00114-7

Harris, J. A. (1998). Using c-fos as a neural marker of pain. Brain Res. Bull. 45, 1-8. doi: 10.1016/s0361-9230(97)00277-3

Hosoya, M., Kawamata, Y., Fukusumi, S., Fujii, R., Habata, Y., Hinuma, S., et al. (2000). Molecular and functional characteristics of APJ - Tissue distribution of mRNA and interaction with the endogenous ligand apelin. J. Biol. Chem. 275, 21061-21067. doi: 10.1074/jbc.M908417199

Kawamata, Y., Fukusumi, S., Hosoya, M., Fujii, R., Hinuma, S., Nishizawa, N., et al. (2001). Molecular properties of apelin: tissue distribution and receptor binding. Biochim. Biophys. Acta 1538, 162-171. doi: 10.1016/s0167-4889(00)00 143-9

Kivell, B., and Prisinzano, T. E. (2010). Kappa opioids and the modulation of pain. Psychopharmacology 210, 109-119. doi: 10.1007/s00213-010-1819-6

Lee, D. K., Cheng, R., Nguyen, T., Fan, T., Kariyawasam, A. P., Liu, Y., et al. (2000). Characterization of apelin, the ligand for the APJ receptor. J. Neurochem. 74, 34-41. doi: 10.1046/j.1471-4159.2000.0740034.x

Lee, D. K., Saldivia, V. R., Nguyen, T., Cheng, R., George, S. R., and O’Dowd, B. F. (2005). Modification of the terminal residue of apelin-13 antagonizes its hypotensive action. Endocrinology 146, 231-236. doi: 10.1210/en.2004-0359

Li, Y., Chen, J., Bai, B., Du, H., Liu, Y., and Liu, H. (2012). Heterodimerization of human apelin and kappa opioid receptors: roles in signal transduction. Cell. Signal. 24, 991-1001. doi: 10.1016/j.cellsig.2011. 12.012

Liu, Y., Zhang, T., Wang, Y., Wu, P., Li, Y., Wang, C., et al. (2019). Apelin13 attenuates early brain injury following subarachnoid hemorrhage via suppressing neuronal apoptosis through the GLP-1R/PI3K/Akt signaling. Biochem. Biophys. Res. Commun. 513, 105-111. doi: 10.1016/j.bbrc.2019.03.151

Luo, H., Xiang, Y., Qu, X., Liu, H., Liu, C., Li, G., et al. (2019). Apelin-13 suppresses neuroinflammation against cognitive deficit in a streptozotocininduced rat model of Alzheimer's disease through activation of BDNFTrkB signaling pathway. Front. Pharmacol. 10:395. doi: 10.3389/fphar.2019. 00395

Lv, S., Zhou, Y., Feng, Y., Zhang, X., Wang, X., Yang, Y., et al. (2020). Peripheral spexin inhibited food intake in mice. Int. J. Endocrinol. 2020:4913785. doi: $10.1155 / 2020 / 4913785$

Lv, S.-Y., Chen, W.-D., and Wang, Y.-D. (2020). The apelin/APJ system in psychosis and neuropathy. Front. Pharmacol. 11:320. doi: 10.3389/fphar.2020. 00320
Lv, S.-Y., Cui, B., Chen, W.-D., and Wang, Y.-D. (2017). Apelin/APJ system: a key therapeutic target for liver disease. Oncotarget 8, 112145-112151. doi: 10.18632/ oncotarget.22841

Lv, S.-Y., Qin, Y.-J., Wang, N.-B., Yang, Y.-J., and Chen, Q. (2012). Supraspinal antinociceptive effect of apelin-13 in a mouse visceral pain model. Peptides 37, 165-170. doi: 10.1016/j.peptides.2012.06.007

Lv, S.-Y., Yang, Y.-J., Hong, S., Wang, N.-B., Qin, Y.-J., Li, W.-X., et al. (2013). Intrathecal apelin-13 produced different actions in formalin test and tail-flick test in mice. Protein Pept. Lett. 20, 926-931. doi: 10.2174/ 0929866511320080010

Maguire, J. J., Kleinz, M. J., Pitkin, S. L., and Davenport, A. P. (2009). Pyr(1) Apelin-13 Identified as the Predominant Apelin Isoform in the Human Heart Vasoactive Mechanisms and Inotropic Action in Disease. Hypertension 54, 598-U296. doi: 10.1161/hypertensionaha.109.134619

Masri, B., Knibiehler, B., and Audigier, Y. (2005). Apelin signalling: a promising pathway from cloning to pharmacology. Cell. Signal. 17, 415-426. doi: 10.1016/ j.cellsig.2004.09.018

McNamara, C. R., Mandel-Brehm, J., Bautista, D. M., Siemens, J., Deranian, K. L. Zhao, M., et al. (2007). TRPA1 mediates formalin-induced pain. Proc. Natl. Acad. Sci. U.S.A. 104, 13525-13530. doi: 10.1073/pnas.0705924104

Medhurst, A. D., Jennings, C. A., Robbins, M. J., Davis, R. P., Ellis, C., Winborn, K. Y., et al. (2003). Pharmacological and immunohistochemical characterization of the APJ receptor and its endogenous ligand apelin. J. Neurochem. 84, 1162-1172. doi: 10.1046/j.1471-4159.2003.01587.x

Meymandi, M.-S., Sepehri, G., and Mobasher, M. (2006). Gabapentin enhances the analgesic response to morphine in acute model of pain in male rats. Pharmacol. Biochem. Behav. 85, 185-189. doi: 10.1016/j.pbb.2006.07.037

Niimi, K., Takahashi, E., and Itakura, C. (2009). Analysis of motor function and dopamine systems of SAMP6 mouse. Physiol. Behav. 96, 464-469. doi: 10.1016/ j.physbeh.2008.11.012

O'Carroll, A.-M., Lolait, S. J., Harris, L. E., and Pope, G. R. (2013). The apelin receptor APJ: journey from an orphan to a multifaceted regulator of homeostasis. J. Endocrinol. 219, R13-R35. doi: 10.1530/joe-13-0227

O'Carroll, A. M., Selby, T. L., Palkovits, M., and Lolait, S. J. (2000). Distribution of mRNA encoding B78/apj, the rat homologue of the human APJ receptor, and its endogenous ligand apelin in brain and peripheral tissues. Biochim. Biophys. Acta 1492, 72-80. doi: 10.1016/s0167-4781(00)00072-5

O’Dowd, B. F., Heiber, M., Chan, A., Heng, H. H., Tsui, L. C., Kennedy, J. L. et al. (1993). A human gene that shows identity with the gene encoding the angiotensin receptor is located on chromosome 11. Gene 136, 355-360. doi: 10.1016/0378-1119(93)90495-o

Ong, W.-Y., Stohler, C. S., and Herr, D. R. (2019). Role of the prefrontal cortex in pain processing. Mol. Neurobiol. 56, 1137-1166. doi: 10.1007/s12035-018$1130-9$

Patel, S. J., Sanjana, N. E., Kishton, R. J., Eidizadeh, A., Vodnala, S. K., Cam, M., et al. (2017). Identification of essential genes for cancer immunotherapy. Nature 548, 537-542. doi: 10.1038/nature23477

Reaux, A., De Mota, N., Skultetyova, I., Lenkei, Z., El Messari, S., Gallatz, K., et al. (2001). Physiological role of a novel neuropeptide, apelin, and its receptor in the rat brain. J. Neurochem. 77, 1085-1096. doi: 10.1046/j.1471-4159.2001. 00320.x

Reeta, K., Mediratta, P. K., Rathi, N., Jain, H., Chugh, C., and Sharma, K. K. (2006). Role of kappa- and delta-opioid receptors in the antinociceptive effect of oxytocin in formalin-induced pain response in mice. Regul. Pept. 135, 85-90. doi: 10.1016/j.regpep.2006.04.004

Rostamzadeh, F., Najafipour, H., Yeganeh-Hajahmadi, M., Esmaeili-mahani, S., Joukar, S., and Iranpour, M. (2017). Heterodimerization of apelin and opioid receptors and cardiac inotropic and lusitropic effects of apelin in $2 \mathrm{~K} 1 \mathrm{C}$ hypertension: role of pERK1/2 and PKC. Life Sci. 191, 24-33. doi: 10.1016/j. lfs.2017.09.044

Shen, P., Yue, Q., Fu, W., Tian, S.-W., and You, Y. (2019). Apelin-13 ameliorates chronic water-immersion restraint stress-induced memory performance deficit through upregulation of BDNF in rats. Neurosci. Lett. 696, 151-155. doi: 10. 1016/j.neulet.2018.11.051

Tatemoto, K., Hosoya, M., Habata, Y., Fujii, R., Kakegawa, T., Zou, M. X., et al. (1998). Isolation and characterization of a novel endogenous peptide ligand for the human APJ receptor. Biochem. Biophys. Res. Commun. 251, 471-476. doi: 10.1006/bbrc.1998.9489 
Tjolsen, A., Berge, O. G., Hunskaar, S., Rosland, J. H., and Hole, K. (1992). The formalin test: an evaluation of the method. Pain 51, 5-17. doi: 10.1016/03043959(92)90003-t

Yang, Y., Lv, S.-Y., Lyu, S.-K., Wu, D., and Chen, Q. (2015). The protective effect of apelin on ischemia/reperfusion injury. Peptides 63, 43-46. doi: 10.1016/j. peptides.2014.11.001

Yang, Y., Lv, S.-Y., Ye, W., and Zhang, L. (2016). Apelin/APJ system and cancer. Clin. Chim. Acta 457, 112-116. doi: 10.1016/j.cca.2016. 04.001

Zhang, Z.-X., Li, E., Yan, J.-P., Fu, W., Shen, P., Tian, S.-W., et al. (2019). Apelin attenuates depressive-like behavior and neuroinflammation in rats co-treated with chronic stress and lipopolysaccharide. Neuropeptides 77, 101959-101959. doi: $10.1016 /$ j.npep. 2019.101959

Zhen, E. Y., Higgs, R. E., and Gutierrez, J. A. (2013). Pyroglutamyl apelin-13 identified as the major apelin isoform in human plasma. Anal. Biochem. 442, 1-9. doi: 10.1016/j.ab.2013.07.006
Zhou, S., Guo, X., Chen, S., Xu, Z., Duan, W., and Zeng, B. (2019) Apelin-13 regulates LPS-induced N9 microglia polarization involving STAT3 signaling pathway. Neuropeptides 2019:101938. doi: 10.1016/j.npep.2019.10 1938

Conflict of Interest: The authors declare that the research was conducted in the absence of any commercial or financial relationships that could be construed as a potential conflict of interest.

Copyright $\odot 2020 \mathrm{Lv}$, Zhang, Feng, Zhou, Cui, Yang and Wang. This is an openaccess article distributed under the terms of the Creative Commons Attribution License (CC BY). The use, distribution or reproduction in other forums is permitted, provided the original author(s) and the copyright owner(s) are credited and that the original publication in this journal is cited, in accordance with accepted academic practice. No use, distribution or reproduction is permitted which does not comply with these terms. 